\title{
THE FOURTH INDUSTRIAL REVOLUTION: MANAGING TECHNOLOGY DEVELOPMENT FOR COMPETITIVENESS
}

\author{
Mohammed Ali Berawi ${ }^{1^{*}}$ \\ ${ }^{1}$ Faculty of Engineering, Universitas Indonesia, Kampus UI Depok, Depok 16424, Indonesia
}

\begin{abstract}
We are in the midst of a fourth industrial revolution, in which technological advances in every aspect of our lives are being integrated. Industry 4.0 has evolved in response to developments in information and data technology. A shift in workplace culture has been highlighted by the Internet of Things (IoT) through the exponential growth of smart devices that connect all things, data, and services, with people. Entire value chains are interconnected by autonomous systems created by intelligent machine and data networks.
\end{abstract}

The unification of effective projects, products, and services is dynamic, with the consequence that entire production systems-across and within companies, industries, and society-are being transformed. The value creation chain over the entire life cycle of products is interconnected, resulting in a fusion of physical and digital worlds. An isolated aspect of the production process is no longer being considered by industry personnel. Instead, integration is being applied from inception to product output, using services supported by new, advanced, and enhanced data collection technology. Technologies such as smart and intelligent machines, artificial intelligence, cyber production systems, and three-dimensional technology are increasingly being used to accelerate product or service competitiveness. The fourth industrial revolution is transforming the economic paradigm and mechanisms used to create value and generate benefits, i.e., efficiency, effectiveness, and customization, as well as quality and innovative products, projects, and services.

The extensive utilization of technological advancements in many smart city sectors, a topical IoTrelated development, has become the most effective way of improving quality of life. Technological breakthroughs impact on the way in which we live, work, and interact in the urban space. The integration of smart cities technologies is becoming more visible and enhancing the lived urban experience.

\section{The Integration of Business Industries}

Technology is arguably one of the most significant forces affecting business competition, and has the ability to change the existing industry processes and to create new industries. Technology is used to reduce operational costs, improve quality, and expedite innovation with the objective of creating sophisticated products and markets. Information and communication technology (ICT) forms the mainstay of innovative solutions. New forms of cost-efficient collaboration between products and services have been enabled by the use of the Internet and digital social media.

Product values are enhanced by the creation of systems that connect the information-processing systems that govern a physical product, thereby increasing the interconnectivity of objects and functions, as well as through access to available data and services online. The use of sensors, the Internet, artificial intelligence, and big data analytics has the potential to transform the way in which goods are manufactured and services are delivered. Advances in technological systems have

\footnotetext{
*Corresponding author's email: maberawi@eng.ui.ac.id, Tel. +62-21-7270029, Fax. +62-21-7270028 Permalink/DOI: https://doi.org/10.14716/ijtech.v9i1.1504
} 
increased flexibility in manufacturing, helped to facilitate mass customization, and ensured better quality and improved productivity.

It is also possible to maximize company revenue by connecting products and services, and through the creation of additional business line functions. The manufacturing, transportation, and processing industries can now be linked through online services. In addition, the use of online transactions has been simplified and expedited by developments in financial technology (Fintech) and other service industries. Thus, the use of an integrated system in which multi functions are combined via a single application is characteristic of the way that business is currently conducted.

Since technological innovation is a significant commercial global force, information technology is being used extensively used to connect business strategies and operations within corporations. Regulation policy and business practices need to be continually updated by leveraging technologies to build, maintain, and enhance the competitive advantage of a country or company, based on advance knowledge and expertise. As a consequence, large-scale collaboration and partnership is required to manage business integration.

\section{The Optimization of Design and Technology Performance}

Engineering design and scientific advances, through research and development, are realized to improve the performance and usefulness of projects, products, and services. We are delighted to be able to include 20 selected papers, whose subject matter is dedicated to technological advancements in project, product, and service design in the current edition of the journal. The papers comprise various studies on design- and technology-related developments that have contributed to improvements in the end-result performance.

An integrated system of enhancing the flexural strength of plastic is described, and was achieved using a combination of fiber-reinforced plastic use, retrofitting, and surface treatment techniques in the study by Tudjono, Lie, and Gan. The authors argue that the proposed method of upgrading the flexural capacity of plastic was instigated as a solution to the repair and restoration of cracked sections.

Reservoir yield was determined and the hydropower potential of Doma Dam in Nigeria was evaluated for power generation purposes in the research conducted by Sule, Adunkpe, and Salami. It was established that the provision of $2 \times 500 \mathrm{Kw}$ Kaplan turbines, operating 12 hours a day, would deliver 2.0-4.0 GWH of energy annually to communities in close proximity to the dam.

An alternative perspective on urban structures is provided in the paper by Fuad, Yatmo, Suganda, and Ibrahim. The authors used a multilayered approach to define the structure of space that arises from its complex use. The nesting approach can be used to reveal structures nesting within the space structure and to depict the mechanism behind overlapping unit structures in urban spaces.

In research by Mohammadi and Mukhtar, it was demonstrated that supply chain reference models for service-oriented architecture can support different stages of information system development. It was determined that appropriate tools, proper methodologies, and formal modelling languages were required to procure a comprehensive and transparent supply chain process model.

The use of value stream mapping to eliminate waste was shown to improve warehouse operations by at least $40 \%$ in research by Baby, Prasanth, and Jebadurai. in which the implementation of lean principles was evaluated, with the objective of improving sales warehouse operations in the manufacturing industry.

A method of optimizing the dry storage design for nuclear-spent fuel was assessed in the study by Ratiko, Samudera, Hindami, Siahaan, Naldi, Hapsari, Mahlia, and Nasruddin. The authors 
demonstrated how the use of a stack effect in a passive cooling system for dry storage decreased the temperature to within safe parameters. Optimum thermal safety and optimization values were found to be $325.1 \mathrm{~K}\left(52.0^{\circ} \mathrm{C}\right)$ and US\$8037.40, respectively.

Taguchi-Grey relational-based multi-response optimization of diesel engine operating parameters, using water-in-diesel emulsion fuel, was evaluated in research by Vellaiyan, Amirthagadeswaran, and Sivasamy. Optimum performance and emission levels were reportedly obtained at a compression ratio of 18 and water concentration of $10 \%$.

Satisfactory goodness of fit $\left(\mathrm{R}_{\mathrm{wp}}=10.42 \%\right)$ and reliability factor $\mathrm{S}$ of 1.7 were provided using the Rietveld refinement technique in the study by Parikin, Dani, Jahja, Iskandar, and Mayer on the crystal structure of ferritic steel for use in multipurpose structural material applications.

The properties of newly identified, precipitation-hardened, austenitic stainless steel, evaluated using transmission electron microscopy, were explored in research by Dani, Parikin, Dimyati, Rivai, and Iskandar. A new type of precipitation was seen to have formed at the grain boundaries. In addition, small coherent plates were distributed homogenously along the grain boundaries and inside the grains.

It was demonstrated in the study by Sadighi, Mohaddecy, and Abbasi that the gross profit to be derived from the hydrocracking process could be enhanced to more than US\$0.81 million annually, having taken all operational constraints into account. This was achieved by optimizing a vacuum gas oil hydrocracking plant using an artificial neural network.

The development and characterization of a composite anthill-chicken eggshell as a catalyst for the production of biodiesel from waste frying oil was explored in the paper by Yusuff, Adeniyi, Olutoye, and Akpan. The synthesized catalyst was reported to convert low-grade oil into biodiesel via a single-step transesterification process.

The effects of metal loading on the performance of a supported tri-metallic catalyst for the synthesis of carbon nanotubes (CNTs) from liquefied petroleum gas were determined in research by Setyopratomo, Wulan, and Sudibandriyo. A high CNT yield was attributed to the high pore volume of the catalyst. The $\mathrm{Fe}-\mathrm{Co}-\mathrm{Mo} / \mathrm{MgO}$ catalyst successfully facilitated the formation and growth of multi-walled CNTs, with ordered structures and a high degree of graphitization.

A design for an ultraviolet light-emitting diode prototype photoreactor for radiation vulcanized natural rubber latex (NRL) was proposed by Widiyati and Poernomo in their research on its ability to obtain irradiated NRL-free carcinogens and allergenic proteins.

The circuit optimization of an 8051 microcontroller is described in the paper by Yeap, Thee, Lai, Nisar, and Krishnan. The proposed design is reportedly capable of operating at $150 \mathrm{MHz}$, with a significant reduction in chip size, and with power consumption of $593.9899 \mu \mathrm{W}$.

Enhanced performance, particularly for molecules with a large number of atoms using a single graphics processing unit (either AMBER, or GTX 790 or 970) was demonstrated in the study by Suhartanto, Yanuar, Wibisono, Hermawan, and Bustamam, with the use of molecular dynamics simulation of the Plasmodium falciparum enoyl-acyl carrier-protein reductase enzyme.

Surface crack detection, using a low-cost photoacoustic imaging system, was evaluated in the study by Setiawan, Suparta, Mitrayana, and Nugroho. The system was demonstrated to be more effective than an electronic imaging system in generating images of cracks, while the material surface greatly facilitated interaction between the laser and itself.

A wavelet transform-based ball-bearing defect detection scheme for use with heavy-duty electric mining motors was appraised in the paper by Sinh, Das, and Chatterjee. The system was subject 
to supply frequency regulation using motor current signature analysis. Minimal equipment, ideal in a grimy, hazardous mining environment, was all that was required using this approach.

The ability to reduce a thermal voltage converter standard using a using a three-stage build-up and -down calibration process method was assessed in the study by Sardjono and Wijonarko. The dissemination process with the best measurement accuracy (of up to $20 \mathrm{ppm}$ ) was successfully obtained for measurement points between $1 \mathrm{~V}$ and $20 \mathrm{~V}$.

An approximation regression analysis method for concurrent big data streaming was evaluated in research by Jittawiriyanukoon and Srisarkun. It was ascertained that the partitioning method used for large data streaming helped to reduce computing time and space requirements, while acceleration improved processing time.

A comparison of the performance of interestingness measures was conducted in the study by Sisodia, Singhal, and Khandal. in order to establish redundant and non-informative web data usage rules. Leverage was found to result in the least number of redundant rules with respect to the top measures and the least informative rules for all the measures in general.

I hope that this special edition of IJTech conveys new insight into the ways in which we conduct research. I will gladly respond to any comment or enquiry that arises regarding the direction or content of the journal, and invite you to join us in this venture by sending in your work to be considered for publication.

With warmest regards from Jakarta,

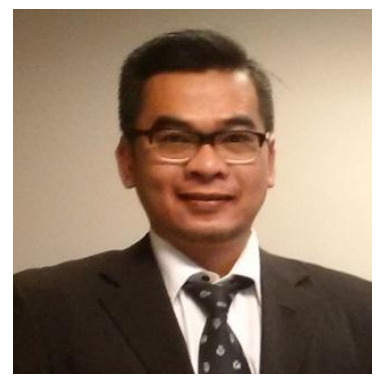

Dr. Mohammed Ali Berawi

Editor in Chief 